\title{
Comparative Study between Teaching Football with Oral and Oral/Graphic Verbalization
}

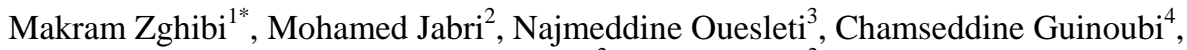 \\ Samira Welhezi ${ }^{2}$, Moez Hamdi ${ }^{2}$ \\ ${ }^{1}$ LASELDI, University of Franche-Comté, Besançon, France \\ ${ }^{2}$ Higher Institute of Sports and Physical Education, Kef, Tunisia \\ ${ }^{3}$ Higher Institute of Education and Training Contained, Tunis, Tunisia \\ ${ }^{4}$ Research Laboratory, “Sports Performance Optimization” National Center of Medicine and Science in Sports \\ (CNMSS), Tunis, Tunisia \\ Email: *makwiss@yahoo.fr
}

Received April 10 $0^{\text {th }}$, 2013; revised May $15^{\text {th }}$, 2013; accepted May $28^{\text {th }}, 2013$

Copyright $@ 2013$ Makram Zghibi et al. This is an open access article distributed under the Creative Commons Attribution License, which permits unrestricted use, distribution, and reproduction in any medium, provided the original work is properly cited.

\begin{abstract}
The aim of this study was to compare two methods of teaching using two different modalities of verbalization: oral and oral/graphic. We opted for a quantitative-comparative analysis of the pupils' language typologies taken from oral and written productions of third secondary grade pupils who play football in a professional club (juniors of Olympic Kef, IInd league, 18 years old on average). The comparisons between the group proceeding to an oral verbalization versus the group using an oral/graphic one as well as intra-groups' comparisons did not show clear significant differences. Despite of a statistical signification absence, we note that the two teams made a progress (increase in the number of played and conquered balls and the shots on target) especially during the last three sessions. Indeed, the debate of ideas is a process. It is relevant that the interaction between learning oral and graphic verbalization is more dynamic, whenever pupils verbalize orally and graphically, they are more motivated to learn.
\end{abstract}

Keywords: Teaching; Oral/Graphic Verbalization; Football; Game

\section{Introduction}

Comparative education collects data about educational systems; it offers an explanation about the links between education and culture (Lê Thành Khôi, 1995). It initiates researches oriented to decisions (international organizations) and also to conclusions: studies on the relationship between education, culture and society (De Landsheere, 1992). Comparative education aims to contribute to a better comprehension (Zerai, 2011). Indeed, by comparing educational facts belonging to different contexts, we are guided to explore other cultures (De Landsheere, 1972). It then passes to a better understanding of our own culture, and discovering relativism but it is necessary to define the field of comparative education previously (Zerai, 2011).

It is in this comparative perspective that this work aimed to compare two methods of teaching using two different modalities of verbalization: oral and oral/graphic.

\section{Methodology}

This study opts for a quantitative analysis of oral and written productions of third secondary grade pupils who play football in a professional club (juniors of Olympic Kef, IInd league, 18 years old on average).

The research protocol proposed in this study lies in the or-

*Corresponding author. ganization of a cycle of ten "one effective-hour" sessions of football (eight hours and a half of motor and verbal practice were observed and recorded). Learning during these sessions will offer an opportunity in which pupils can exchange ideas freely to build action projects. This creates among pupils/players the search for answers to the problems encountered during the game. The proposed sessions are all based on game situations on a handball pitch $(40 \mathrm{~m} \times 20 \mathrm{~m})$. Each session (session's body) consists in two game situations (two matches) controlled by the teacher and separated by a five minutes sequence of debate of ideas (Gréhaigne et al., 1998) provided by two specialist teachers.

Therefore, it is a comparative analysis aiming to convey the pupils' language typologies through analytical models of analyze taken from the sciences of language (Roulet, 1987). The aims of this experiment are to allow to all the pupils to participate in the process of knowledge building via the lived game situations. They are called to analyze and understand what is happening during the play situation in order to build an action project and check whether it is actually applied on the pitch.

The Figure 1 shows the experiment steps: pupils play for ten minutes, and then verbalize during five minutes before to return to play again (another $10 \mathrm{~min}$ ) to implement the action project set by each team. During the verbalization sequences, pupils discuss their action project to solve the problems experienced in the first situation of the game. The debate of ideas is a space for dialogue that allows to learners to negotiate the meaning of 


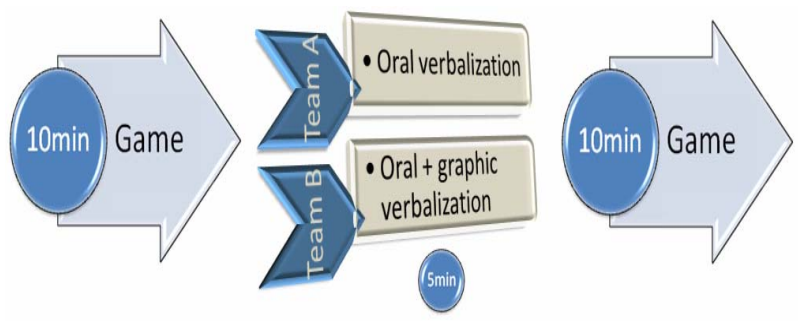

Figure 1.

Global structure of the ideas' debate situation.

game action. The second game situation is performed to check whether the action project is done or not. The situation of ideas' debate is organized to allow for students to exchange their intentions about the action orally or graphically (Chang, 2009). In other words, the teacher provides:

- A sequence of verbalization (oral) for Team A (students discuss verbally about the game).

- A sequence of verbalization (oral and graphic) for Team B (students discuss verbally about the game so they can simultaneously draw the action strategies to be followed during the following played situation).

In this work we will pass from a classic behaviorist conception that considers the teacher as a designer of situations and ready solutions provider to a constructivist conception where the teacher is a mediator of knowledge (Zghibi, 2009). During the debate of ideas, the teacher is a manager of interlocutions reviving pupils' thinking, without taking a position (Nachon, 2004). According to Pieron (2000), the quality of education depends on the teacher's attitude, his interventions, his knowledge and his vision of learning. From our choice of teachers, roles will be divided as follows: the first teacher controls the oral verbalization with the Team $\mathrm{A}$, the second one assures verbal and graphic verbalization with Team $B$.

For pedagogical reasons and since the level of boys is very high comparing to the girls, the study was conducted on a sample composed only by masculine subjects. It should be noted that Football is a popular sport practiced in the streets and quarters mainly by boys in the region of Kef.

The sample consists of 14 boys in the third year of secondary school. The subjects were further divided into two equal subgroups (in number and strength).

This choice is based on the fact that didactic studies recognize that at this level, the pupils are generally able to analyze, understand and especially to problematize independently from the teacher. Thus, they participate in the process of construction of knowledge, referring to the proposed situations and looking for ways to deal with the problems. This is part of the didactic principle of Gréhaigne (1992) "understand to succeed" which allows the problematization of the difficulties encountered during the action.

Each team is composed by seven players: 5 pupils play and 2 others (substitutions) make observation and participate systematically and regularly. We note that the substitutions and the switch of goalkeepers are done by the pupils themselves and independently of the intervention of teachers.

This choice can be also justified by the fact that in a tactical approach or even a semio-linguistic one, it would be better to give pupils free choice to fend for themselves during the game (Gréhaigne, 2009). According to this conception, learning is done in problem-solving situations favoring a generalization of learned content. The learner plays an important role in determining the process of the game.

We used three cameras during played situations and verbalization sequences: a fixed one to record the game situations and two mobile cameras recording the pupils' discussion sequences of pupils.

We opted for an observation grid concerning game indicators (Gréhaigne, Billiards, \& Laroche, 1999). This tool was developed to assess the power balance in football in order to better describe the evolution of adversarial relationships. These indicators are: playing volume (total number of played balls), defensive capacities (balls won from the opponent), adaptation to the game (number of lost balls), players' offensive capacities (shots on target) and efficiency index (goals scored).

\section{Results}

This section focuses on the comparison between the results of the two types of teaching with: oral and oral/graphic verbalization. As for comparisons between groups A and B, intragroups' comparisons did not show significant differences. Only one significant improvement was detected concerning the number of played balls for the Group B after the development of action projects comparing to played balls before.

We note, despite of a signification absence, that for the two teams the number of played and conquered balls together with the number of shots on target tend to increase. As we did use a purposive sampling, the number as well as the duration of sessions and game phases can be the reason of the absence of significations and this without affecting neither the improvements nor the utility of the debate phases.

\section{Team A}

There is no significant difference throughout the eight sessions between the number of lost balls during the first sequence and those recorded during the second sequence. The number of balls lost by interception before and after each sequence of verbalization evolved from the first to the last session from 21 to 17,13 to 14,11 to 22,18 to 20,18 to 19,24 to 27,20 to 25 and 26 to 31 (Figure 2). This indicator provides information about the playing volume developed in confrontation and informs about how the ball is exchanged between the partners and the number of successful passes. The idea is to see the quality evolution of the passes exchanged between the same team strikers. A played ball is counted when a team comes into possession. The team is now in position to keep the ball and decide next moves. Therefore, the quality of play is dependent on the

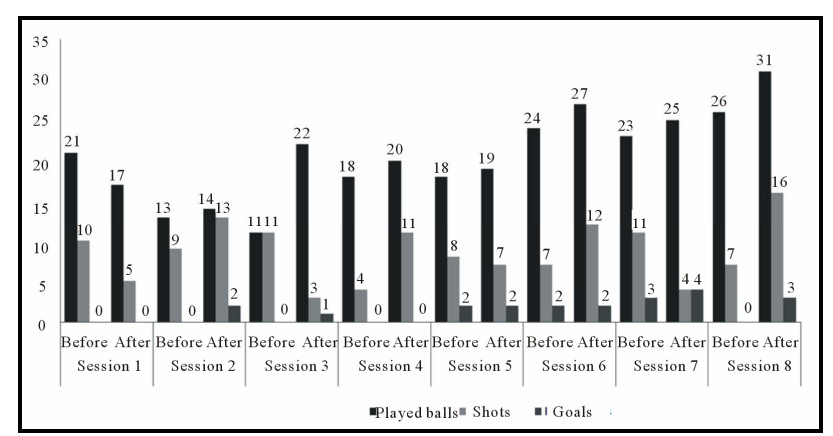

Figure 2.

Direct effects of oral verbalization on the game parameters. 
number of played balls: the more this number is important the better the game is in a given unit of time.

We note that during all the cycle except the first and fourth session, the number of shots is more important during the game following the sequence of verbalization. As shown in the Figure 2, the evolution during the eight sessions is respectively from 10 to 5,9 to 13,11 to 3,4 to 11,8 to 7,7 to 12,11 to 14 and 7 to 16 . Shooting a ball here is an action that can score goals and thus increase the team score. In football, shooting is an indicator of major importance that informs about the offensive capacities' improvement. Moreover, victory in team sports, especially football, depends on the number of scored goals. This indicator provides information about the team offensive efficiency and the degree of scoring among balls shot on target. During the eight sessions, we passed respectively from 0 goals before verbalization sequence to 0 goals to after this sequence, 0 to 2,0 to 1,0 to 0,2 to 2,2 to 2,3 to 4 and from 0 to 3 in the last session.

\section{Team B}

During the eight sessions, the difference in the played balls before/after verbalization is significant. There was a significant improvement $(\mathrm{p}<0.05)$ in the number of balls played after the verbalization. Thus, we passed respectively from 16 played balls before to 15 after the sequence of verbalization for the first session, from 18 to 18 in the 2nd, 19 to 18 in the 3rd, 1620 in the 4th, 21 to 27 in the 5th, 24 to 27 in the 6th, 29 to 33 7th and finally from 32 to 39 during the last session. Figure $\mathbf{3}$ shows this evolution.

There is no continuous progression on the shots on target realized during the games following the verbalization sequence comparing to the first games. It passes respectively during the eight sessions from 9 shots for the first game to 12 in the second in the first session, from 5 to 4,4 to 9,16 to 3,11 to 8,3 to 3,14 to 11 and from 15 to 14 during the eighth session. The same observation is noted concerning the goals scored with respectively 1 to 3 in the first session, 0 to 0 in the second session, 1 to 1 ( $3^{\text {rd }}, 4^{\text {th }}$ and $5^{\text {th }}$ sessions $), 0$ to 0 in the $6^{\text {th }}$ session, 3 to 3 in the $7^{\text {th }}$ session and from 1 to 2 goals in the last session.

\section{Discussion of the Main Findings}

The only significance is denoted about the played balls for Team B which received an apprenticeship using oral and graphic verbalization. This evolution in the played balls can be explained by the tendency to manage more ball possession. The efficiency of pupils' oral/graphic verbalization appears via the

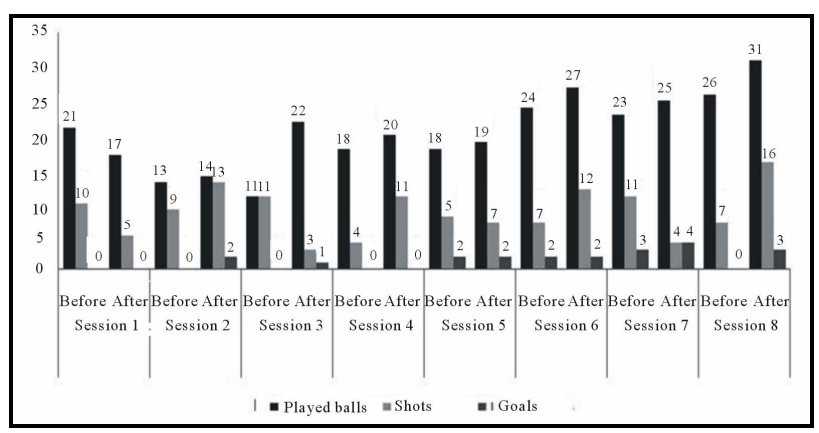

Figure 3.

Direct effects of oral/graphic verbalization on the game parameters. implementation of decisions already taken in verbalization sequences. Players produce speech acts in order to subsequently make sense to the game (Wallian \& Gréhaigne, 2004). We can say that the interaction between learning and oral and graphic verbalization is dynamic. We also note that whenever pupils verbalize orally and graphically, they are more motivated to learn. In other words, the debate of ideas is a process that tends to help on resolving problems.

Despite it's a relation of power opposition continuously, we note that the two teams made a progress and especially during the last three sessions. This can be explained by the fact that both teams are able to take into account how the other team plays and to propose a combined technical-tactical solutions adapted to the opposing team abilities. However, the problem of the presence of the opponent appears in all the verbalization sequences. This shows that the players of both teams are able to take into account the intentionality of opponents.

The semio-constructivism gives great importance to the process by which learner can co-construct his knowledge and actions from his experiences. Indeed, the players try through these verbalization sequences to think about their played experiences, to negotiate about the available solutions, and to co-construct action rules as action projects and achieve them collectively during the second situation (Grehaigne, 2009).

The realization of action projects in the last three sessions can be explained by the fact that pupils have begun to create new relationships with their teammates. These relationships are based on some agreement that results in a realizable action project (Lave \& Wenger, 1991).

The debate of ideas helps players to manage information better, which leads to the conclusion that they do not learn randomly, nor assimilate passively what others teach them. Learning is a product of experience: it is easier when the experience is deliberately and systematically searched by the learner. The debate of ideas is thus an interaction between what we have in mind and what others think.

The game situation highlights the difficulty of individual choice decisions, design the most appropriate response each time that the problem situation is not familiar or predictable. The use of the debate of ideas between pupils guides to a modification of cognitive structures.

Linguistic processes promote awareness and the emergence of effective action projects. That is how learning becomes more predictable and there will be a better match between the answer ssand the game situation in the future.

Construction of new knowledge is the result of a long history of interaction between the different responses to problem situations caused by the game and forecasts of actions planned during verbalizations. The interaction between pupils produces the development and the modification of individual representations (Wallian \& Chang, 2007; Zghibi et al., 2013a).

By better managing the organization of what we know, we can enrich indefinitely our ability to solve a problem such as a better space management via the calculation of pass' distance, opponents' location and moves. If tactical skills are, in part, built thanks to these cognitive tools, verbal interactions between peers help obviously for their development.

The analysis of the discourses made during the debate of ideas could help the pupils to understand better if the proposals are likely to be successful or to fail (Zghibi et al., 2013b). Thus, they learn to limit their learning objectives and have reasonable expectations about what they can accomplish. However, while 
learning, pupils do not need to be told what to do. Learning to act in play, with the emergence of action projects, participate in pupils' cognitive development, particularly in the construction of structured thinking.

\section{Conclusion}

During this learning cycle we noticed that pupils who attended a verbalization with graphic schematization (Team B) show a significant increase in the number of played balls. This is reflected in the immediate change of the game strategy, the rapid counterattacks and a more developed analysis of the game context. Thus, the players have passed a first level to go to a more advanced, more consisting one; mainly concerning the "played balls" parameter. This can also be justified by the number of projects implemented by the pupils during the last three sessions. Team A has also experienced increases especially during the last 3 sessions but remain statistically not significant.

Thereby this study about discursive productions highlights the importance of verbalization in the football teaching/learning system in Tunisia, with either oral or graphic verbalization.

This study presents some limits: methodological and linguistic limitations. Concerning the first category, the sample used in the experimental protocol is so small to generalize the results. The number of sessions itself (eight) does not allow us to prove more significant results. In addition, this study did not consider neither the discourse of the teacher nor the pupil discourse during the game.

As for language difficulties, it is noted that on the one hand, the translation is not perfect. Instead it presents multiple discursive weaknesses. On the other hand, the model we used in discourse analysis doesn't allow studying all the details and specificities of the pupils' discourse. In addition, other means of communication come into play without being taken into account such as gestures, laughter, facial expressions, etc. (Zghibi, 2012).

\section{REFERENCES}

De Landsheere V. (1992). Education and formation. Paris: University Press

De Landsheere G. (1972). Experimental comparative education. In
Dictionary of Evaluation and Research in Education. Paris: France University Press.

Gréhaigne, J. F. (1992). Game organasation in football. Paris : ACTIO.

Gréhaigne, J. F. (2009). Around time. Spaces, learning, projects in team sports. Besançon: University Press of Franche-Comté.

Gréhaigne, J. F., \& Godbout, P. (1998). Formative assessment in team sports with a tactical approach. Journal of Physical Education, Recreation and Dance, 69, 46-51. doi:10.1080/07303084.1998.10605048

Gréhaigne, J. F., Billard, M., \& Laroche, J. Y. (1999). Collective sports teaching at school. Paris: Bruxelles.

Lave, J., \& Wenger, E. (1991). Situated learning. Cambridge: University Press.

Lê Thanh Khôi (1995). Education and Civilisations. Yesterday’s Societies. Paris: UNESCO, BlE, Nathan.

Nachon, M. (2004). Interaction on physical and sportive education: The case of Basketball. Semio-linguistics kills approachand knowledge construction. Besançon: University of Franche-Comté.

Pieron, M. (2000). Sport and teaching. Liège: King Baudouin Foundation's edition.

Roulet, E., Auchlin, A., Moeschler, J., Rubattel, C., \& Schelling, M. (1985). The articulation of discourse on contemporary French. Berne: Lang.

Van Daele H. (1993). Comparative education. Paris: France University Press.

Wallian, N., \& Chang, C. W. (2007). Semiotics of motor action and language activities: to an epistemology of the co-constructed team sports knowledge. In J. F. Gréhaigne (Ed.), Game configurations. Debate of ideas and learning in football and team sports (pp. 145164). Besançon: PUFC.

Wallian, N., \& Gréhaigne, J.F. (2004). To a semio-constructivist approach in motor learning. In G. Carlier (Ed.), If we spoke about the pleasure of physical education teaching (pp. 167-179). Montpellier: AFRAPS.

Zghibi, M. (2012). Semio-constructivist approached learning in Football. Berlin: European University Editions.

Zghibi, M., Sahli, H., Bennour, N., Guinoubi, Ch., Guerchi, M., \& Hamdi, M. (2013b). The Pupil's discourse and action projects: The case of third year high school pupils in Tunisia. Creative Education, 4, 165-171.

Zghibi, M., Gunoubi, Ch., Bennour, N., Jbeli, M., Sahli, F., \& Jabri, M. (2013a). Evolution of language productions and action rules extraction: Case study of an 8th grade class girls during a Handball cycle. Creative Education, 4, 172-179.

Zerai, Z. (2011). Handball learning among Tunisian and French young ladies: verbalization effect. Sport sciences non published Ph.D. Thesis, Franche comté. University. 